\title{
Umedecimento do substrato e temperatura na germinação e vigor de sementes de melão
}

\section{Moistening of the substrate and temperature on germination and vigor of melon seeds}

\author{
Hugo Tiago Ribeiro Amaro ${ }^{1 *}$; Andréia Márcia Santos de Souza David²; \\ Lucas Vinícius de Souza Cangussúí; Bruno Rafael Alves Rodrigues ${ }^{3}$; \\ Miquéias de Oliveira Assis ${ }^{3}$; Cecília Soares Veloso ${ }^{3}$
}

\section{Resumo}

O presente trabalho foi conduzido com o objetivo de avaliar diferentes volumes de água destilada no substrato e temperaturas na germinação e no vigor de sementes de melão, variedade pepino. $\mathrm{O}$ experimento foi conduzido no Laboratório de Análise de Sementes da Unimontes, no período de fevereiro a abril de 2012. A semeadura foi realizada em rolos de papel do tipo "germitest", umedecidos com volumes $(\mathrm{mL})$ de água destilada equivalentes a 1,$0 ; 1,5 ; 2,0 ; 2,5$ e 3,0 vezes o peso do substrato seco, sem adição posterior de água, com três folhas por rolo. Os rolos foram mantidos em germinadores previamente regulados nas temperaturas constantes de 25 e $30^{\circ} \mathrm{C}$ e alternada de $20-30^{\circ} \mathrm{C}$. O delineamento experimental utilizado foi o inteiramente casualizado, em esquema fatorial 5 x 3 (volumes de água destilada e temperaturas), com quatro repetições de 50 sementes. Avaliou-se a porcentagem de germinação, índice de velocidade de germinação, comprimento de raiz e parte aérea, massa fresca e seca de plântulas. Diante dos resultados, conclui-se que as combinações de volume de água destilada no substrato e a temperatura de exposição que proporcionam melhores respostas na germinação e no vigor das sementes de melão, variedade pepino, são de 1,0 vez o peso do substrato seco na temperatura de $30^{\circ} \mathrm{C}$ e 3,0 vezes o peso do substrato seco a 25 e $20-30^{\circ} \mathrm{C}$. Dentre as temperaturas estudadas, a temperatura de $30^{\circ} \mathrm{C}$ promove melhores respostas em todas as variáveis analisadas, sendo recomendada como temperatura adicional para avaliação da qualidade fisiológica de sementes de melão.

Palavras-chave: Cucumis melo L., análise de sementes, teste de germinação

\begin{abstract}
This study was conducted to evaluate different volumes of distilled water and substrate temperatures on germination and vigor of melon, cucumber variety. The experiment was conducted at the Laboratory of Seed Analysis Unimontes in the period february to april 2012. Sowing was done on paper rolls like "germitest" moistened with volumes $(\mathrm{mL})$ of distilled water equivalent to $1.0 ; 1.5 ; 2.0 ; 2.5$ and 3.0 times the weight of dry substrate without further addition of water, with three sheets per roll. The rolls were kept in germination preset constant temperatures of 25 to $30^{\circ} \mathrm{C}$ and $20-30^{\circ} \mathrm{C}$ alternate. The experimental design was completely randomized in a factorial $5 \times 3$ (distilled water volume an temperatures), with four replicates of 50 seeds. We evaluated the germination percentage, germination velocity index, root

\footnotetext{
${ }^{1}$ Eng $^{\circ}$ Agr $^{\circ}$, Discente de Doutorado em Fitotecnia, Universidade Federal de Viçosa, UFV, Viçosa, MG. E-mail: htiagoamaro@ yahoo.com.br

2 Eng $^{\mathrm{a}}$ Agr $^{\mathrm{a}}$, Prof ${ }^{\mathrm{a}}$ do Dept ${ }^{\mathrm{o}}$ de Ciências Agrárias, Universidade Estadual de Montes Claros, UNIMONTES, Campus Janaúba, MG. E-mail: andreia.david@unimontes.br

${ }^{3}$ Discentes em Agronomia, Dept ${ }^{\circ}$ de Ciências Agrárias, Universidade Estadual de Montes Claros, UNIMONTES, Campus Janaúba, MG. E-mail: lucasvscagro@hotmail.com; rafabrunoalves@hotmail.com; mick_eafsal@hotmail.com; cecyveloso@hotmail.com * Autor para correspondência
} 
length and shoot, fresh and dry weight of seedlings. Given the results, it is concluded that combinations of substrate distilled water volume and temperature of exposure that provide better answers on germination and vigor of melon seeds, cucumber variety, are 1.0 times the weight of dry substrate at a temperature of $30^{\circ} \mathrm{C}$ and 3.0 times the dry weight of the substrate 25 and $20-30^{\circ} \mathrm{C}$. Among the studied temperatures, the temperature of $30^{\circ} \mathrm{C}$ promotes better responses in all variables, is recommended as an additional temperature to evaluate the physiological quality of melon seeds.

Key words: Cucumis melo L., seeds analysis, germination test

\section{Introdução}

A utilização de sementes de elevada qualidade fisiológica é de grande importância para o estabelecimento e manutenção de áreas produtivas, crescendo a necessidade de monitorar cada fase da indústria de sementes (ALVES et al., 2005). O desenvolvimento e padronização de testes para a avaliação da qualidade fisiológica em sementes é parte extremamente importante do processo, não só pela garantia que o uso de sementes de qualidade pode proporcionar na obtenção de altas produtividades, mas também pela exigência crescente do mercado consumidor (CARVALHO; FRANÇA NETO; KRZYZANOWSKI, 2006).

Nos laboratórios de análise de sementes, o teste de germinação é o procedimento oficial para avaliação da qualidade fisiológica das mesmas. Os resultados do teste de germinação devem refletir a capacidade das sementes em originar plântulas normais, sob condições e limites estabelecidos nas Regras para Análise de Sementes - RAS (BRASIL, 2009).

O melão (Cucumis melo L.) é uma espécie olerícola muito consumida e de grande popularidade no mundo. No Brasil, planta-se principalmente cultivares de melão do grupo Inodorus, tipo "amarelo", entretanto, há uma tendência de mercado no aumento da demanda por melões do grupo Cantalupensis, aromáticos, de polpa salmão, etc, apresentando novas oportunidades de mercado (COSTA, 2005). Mesmo com o destaque comercial do meloeiro, têm sido poucos os estudos que avaliam os fatores que atuam sobre o processo germinativo da cultura, uma vez que verifica-se problemas na germinação de diversas espécies do gênero Cucumis (BRASIL, 2009), como o melão.
Dentre os fatores que atuam sobre a germinação, a temperatura apresenta grande influência tanto na porcentagem como na velocidade de germinação das sementes, estando relacionada às reações bioquímicas que regulam o metabolismo necessário para iniciar o processo germinativo (CARVALHO; NAKAGAWA, 2000). A resposta da germinação em relação à temperatura depende da espécie, variedade, região de origem e tempo de armazenamento, porém, seu efeito na germinação pode ser expresso em temperaturas mínimas, ótimas e máximas, nas quais a germinação pode ocorrer. A faixa de temperatura ótima é aquela que permite a maior porcentagem de germinação no menor espaço de tempo.

No teste padrão de germinação, deve-se dar atenção especial também ao substrato de semeadura, necessitando permanecer uniformemente úmido, a fim de suprir às sementes da quantidade de água necessária para sua germinação e desenvolvimento. $\mathrm{O}$ excesso de água no substrato pode prejudicar o processo germinativo devido à menor aeração (MARCOS FILHO, 2005). A padronização do volume de água no substrato que favoreça a germinação, conforme a espécie, provavelmente minimizaria as variações nos resultados dos testes, uma vez que as recomendações das RAS (BRASIL, 2009) não atendem a todas as espécies, necessitando de estudos que ajustem as reais respostas da germinação em função do volume de água utilizado.

Nesse sentido, o presente trabalho foi conduzido com o objetivo de avaliar diferentes volumes de água no substrato e temperaturas na germinação e no vigor de sementes de melão, variedade pepino. 


\section{Material e Métodos}

O experimento foi conduzido no Laboratório de Análise de Sementes, do Departamento de Ciências Agrárias da Universidade Estadual de Montes Claros - (DCA/UNIMONTES), Campus Janaúba-MG, durante o período de fevereiro a abril de 2012. As sementes utilizadas no experimento foram extraídas de frutos maduros de meloeiro, da variedade pepino (Cucumis melo var. cantalupensis), produzidos na região de Janaúba, conduzido em sistema de cultivo convencional.

O município de Janaúba localiza-se na latitude de $15^{\circ} 49^{\prime} 51,5^{\prime \prime} \mathrm{S}$ e $43^{\circ} 16^{\prime} 18,2^{\prime}$ ' W, a uma altitude de aproximadamente $540 \mathrm{~m}$. O clima da região, de acordo com a classificação de Köppen, é do tipo "Aw" (tropical quente apresentando inverno frio e seco), com precipitação pluviométrica média de 870 $\mathrm{mm}$, temperatura média anual de $24^{\circ} \mathrm{C}$, umidade relativa média de $65 \%$.

Após a colheita dos frutos e extração das sementes, estas foram lavadas em água corrente até a retirada total da polpa aderida, sendo espalhadas sobre papel toalha, permanecendo à sombra por 24 horas. Após o beneficiamento, as sementes foram armazenadas em sacos de papel, em ambiente controlado $\left(25^{\circ} \mathrm{C}\right.$ e $50 \%$ de UR), até o inicio das avaliações.

Antes da instalação do experimento, verificouse o teor de água das sementes, determinado pelo método de estufa a $105 \pm 3^{\circ} \mathrm{C}$ por 24 horas (BRASIL, 2009), com os resultados expressos em $\%$. Em seguida, as sementes foram submetidas aos seguintes testes:

Germinação: as sementes foram submetidas ao teste de germinação em rolos de papel do tipo "germitest", umedecidos com volumes $(\mathrm{mL})$ de água destilada equivalentes a 1,0; 1,5;2,0; 2,5 e 3,0 vezes o peso do substrato seco, sem adição posterior de água, com três folhas de papel por rolo. Para cada tratamento, utilizaram-se quatro repetições de 50 sementes. Após a confecção dos rolos, estes foram colocados em germinadores digitais, previamente regulados às temperaturas constantes de $25 \mathrm{e}$ $30^{\circ} \mathrm{C}$ e alternada de $20-30^{\circ} \mathrm{C}$. As avaliações foram realizadas no oitavo dia após a instalação do teste, e os resultados expressos em porcentagem, segundo recomendação das RAS (BRASIL, 2009).

Índice de velocidade de germinação: foi conduzido em conjunto com o teste de germinação, anotando-se diariamente, no mesmo horário, o número de plântulas normais emergidas, até a última contagem. Ao final do teste, com os dados diários do número de plântulas emergidas, foi calculado o índice de velocidade de germinação, empregandose a fórmula proposta por Maguire (1962).

Comprimento de raízes e parte aérea: no final do teste de germinação foi determinado, com o auxílio de uma régua graduada $\mathrm{em} \mathrm{cm}$, o comprimento de raízes e da parte aérea de todas as plântulas consideradas normais, sendo os resultados expressos em centímetros. Após avaliou-se a massa fresca e seca das plântulas, sendo acondicionadas em sacos de papel, pesadas em balança com precisão de $0,0001 \mathrm{~g}$ para obtenção da massa fresca, e submetidas à secagem em estufa com circulação de ar $\left(65 \pm 3^{\circ} \mathrm{C}\right)$ durante 72 horas, obtendo a massa seca de plântulas, com resultados expressos em gramas.

O delineamento experimental adotado foi $\mathrm{o}$ inteiramente casualizado, em esquema fatorial 5 x 3 (cinco volumes de água destilada e três temperaturas), utilizando-se quatro repetições de 50 sementes por tratamento. Os dados não foram transformados por terem atendido às pressuposições dos testes de normalidade e de homogeneidade, sendo submetidos à análise de variância. Os efeitos dos volumes de água foram estudados por análise de regressão, escolhendo-se os modelos adequados para representá-los em função do seu comportamento biológico, da significância dos coeficientes do modelo e do valor do coeficiente de determinação $\left(\mathrm{R}^{2}\right)$ e os efeitos das temperaturas foram estudados pelo teste de Tukey a 5\% de significância. 


\section{Resultados e Discussão}

A determinação do teor de água, como procedimento inicial para a avaliação da qualidade fisiológica, indicou que as sementes de melão apresentavam-se com grau de umidade de 9,1\%.

Na Tabela 1 encontra-se o resumo da análise de variância dos dados referentes à qualidade fisiológica das sementes. A interação entre os fatores volumes de água $(\mathrm{V}) \mathrm{x}$ temperaturas $(\mathrm{T})$ foi significativa para as variáveis germinação, índice de velocidade de germinação e massa fresca de plântulas. Houve efeito significativo dos fatores isolados, volumes de água e temperaturas, para todas as variáveis estudadas.

Tabela 1. Valores de "F" resultantes das análises estatísticas referentes a germinação (GE), índice de velocidade de germinação (IVG), comprimento de raíz (CR), comprimento de parte aérea (CPA) e massa fresca de plântulas (MF) de melão, em função dos volumes de água destilada no substrato de germinação e temperaturas. Janaúba, MG. 2012.

\begin{tabular}{lcccrrr}
\hline \multirow{2}{*}{ Fontes de variação } & \multirow{2}{*}{ GL } & \multicolumn{6}{c}{ Variáveis } \\
\cline { 3 - 6 } & & GE & IVG & CR & CPA & \multicolumn{1}{c}{ MF } \\
\hline Vol. Água (V) & 4 & $14,44^{* *}$ & $14,85^{* *}$ & $5,50^{* *}$ & $3,79^{* *}$ & $13,20^{* *}$ \\
Temperatura (T) & 2 & $134,57^{* *}$ & $77,24^{* *}$ & $30,51^{* *}$ & $192,33^{* *}$ & $151,17^{* *}$ \\
Vx T & 8 & $9,09^{* *}$ & $8,49^{* *}$ & $0,82 \mathrm{~ns}$ & $1,30 \mathrm{~ns}$ & $9,50^{* *}$ \\
\hline CV\%- & & 14,51 & 10,43 & 11,47 & 15,56 & 18,74 \\
\hline
\end{tabular}

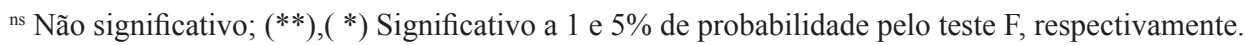

$\mathrm{V}$ (volume de água destilada no substrato de germinação) e T (temperaturas).

Fonte: Elaboração dos autores.

O desdobramento da interação V x T, estudando o efeito de temperaturas dentro de cada volume de água no substrato, revelou comportamento diferenciado entre as temperaturas estudadas, conforme os dados apresentados na Tabela 2. A temperatura de $30^{\circ} \mathrm{C}$ promoveu melhores respostas na germinação das sementes na maioria dos volumes de água estudados. Assim, vale salientar que, mesmo a temperatura de $30^{\circ} \mathrm{C}$ não sendo recomendada pelas RAS (BRASIL, 2009) para avaliação da germinação de sementes de melão, a temperatura maior $\left(30^{\circ} \mathrm{C}\right)$ foi mais eficiente, justificando a necessidade de estudos que permitam a reavaliação dos fatores que afetam o processo germinativo.

A germinação envolve uma série de reações metabólicas que dependem da atividade de sistemas enzimáticos complexos. Durante a germinação, enzimas hidrolisam reservas endospérmicas em uma forma que possam ser utilizadas pelo eixo em desenvolvimento. No início da hidratação, enzimas hidrolíticas tais como amilases, endo-b-mananase e b-glucanases são ativadas no embrião (GANGULI; SEM-MANDI, 1993). A eficiência dessas reações está relacionada à fatores importantes, entre os quais se destaca a temperatura. Machado et al. (2002) observaram que a temperatura ótima para a germinação pode variar em função da condição fisiológica da semente, como o grau de maturidade e o vigor. Segundo esses mesmos autores, a temperatura ótima para a maioria das espécies tropicais encontra-se entre 15 e $30^{\circ} \mathrm{C}$ e a máxima entre 35 e $40^{\circ} \mathrm{C}$. 
Tabela 2. Germinação (\%) de sementes de melão, submetidas a diferentes temperaturas e volumes de água destilada no substrato de germinação. Janaúba, MG. 2012.

\begin{tabular}{ccccc}
\hline Volume de água & \multicolumn{3}{c}{ Temperatura $\left({ }^{\circ} \mathrm{C}\right)$} & Médias \\
\cline { 2 - 4 } destilada $(\mathrm{mL})$ & $20-30$ & 25 & 30 & 51 \\
\hline 1 & $36 \mathrm{~b}$ & $28 \mathrm{~b}$ & $91 \mathrm{a}$ & 52 \\
1,5 & $21 \mathrm{c}$ & $45 \mathrm{~b}$ & $91 \mathrm{a}$ & 47 \\
2 & $14 \mathrm{~b}$ & $57 \mathrm{a}$ & $70 \mathrm{a}$ & 57 \\
2,5 & $46 \mathrm{~b}$ & $52 \mathrm{~b}$ & $74 \mathrm{a}$ & 74 \\
3 & $62 \mathrm{~b}$ & $71 \mathrm{~b}$ & $89 \mathrm{a}$ & 74 \\
\hline
\end{tabular}

*Médias seguidas por letras distintas nas linhas, diferem estatisticamente entre si pelo teste Tukey, a 5\% de probabilidade.

Fonte: Elaboração dos autores.

A germinação das sementes foi influenciada pelo volume de água no substrato, onde os resultados assumiram comportamento quadrático (Figura 1). A maior porcentagem de germinação $(95 \%)$ foi obtida quando as sementes foram expostas a temperatura de $30^{\circ} \mathrm{C}$, com volume de água de 1,0 vez o peso do substrato seco, no entanto, a partir deste volume a germinação foi afetada negativamente até a quantidade de água equivalente a 2,0 vezes o peso do papel. A partir desse ponto, houve uma retomada da curva, encerrando com $86 \%$ de germinação ao se utilizar o volume de água 3,0 vezes o peso do substrato seco.

Figura 1. Germinação (\%) de sementes de melão, submetidas a diferentes temperaturas e volumes de água destilada no substrato de germinação. Janaúba, MG. 2012.

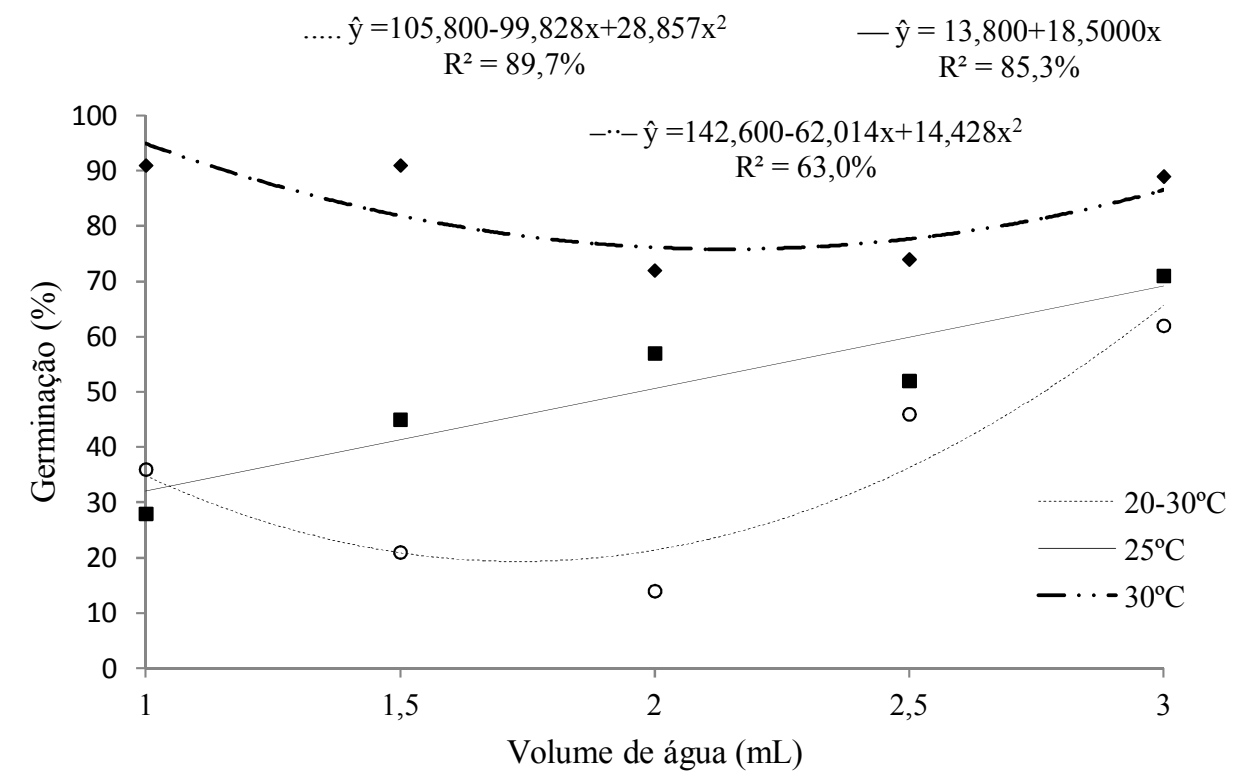

Fonte: Elaboração dos autores. 
$\mathrm{Na}$ temperatura de $25^{\circ} \mathrm{C}$, verificou-se um aumento linear na porcentagem de germinação das sementes, em função do aumento do volume de água utilizado no substrato, sendo que os melhores resultados $(69,3 \%)$ foram observados após adição de água em volume equivalente a 3,0 vezes o peso do substrato seco. Para a temperatura alternada de $20-30^{\circ} \mathrm{C}$, foi necessário o volume de água igual a 3,0 vezes o peso do substrato para obter o máximo de germinação (66\%), ressaltando que esses valores foram inferiores quando comparados aos obtidos com as demais temperaturas avaliadas (Figura 1).

O umedecimento do substrato com volume de água igual a 3,0 vezes o peso do substrato foi prejudicial à germinação de sementes de maxixe (GENTIL; TORRES, 2001). Já Azeredo et al. (2010) verificaram que os teores de água, na faixa de 2,0 a 2,5 vezes o peso do substrato, foram favoráveis à germinação das sementes de repolho. Entretanto, Varela, Ramos e Melo (2005) observaram que, para sementes de angelim-pedra (Dinizia excelsa Ducke), as umidades na faixa de 1,5 até 3,0 vezes o peso do substrato foram favoráveis à germinação das sementes, tolerando uma faixa de amplitude de umedecimento do substrato superior à das sementes de outras espécies agrícolas. Nesse sentido, Vicente, Noronha e Silberschmidt (1969) salientam que a germinação mais favorável pode não ser induzida por somente um volume de água, mas por diversos volumes que ocupam uma faixa de amplitude específica, conforme a espécie.

Os resultados do índice de velocidade germinação confirmaram a mesma tendência observada na germinação, onde a temperatura de $30^{\circ} \mathrm{C}$ foi mais eficiente em promover uma maior velocidade de germinação (Tabela 3). Nesse sentido, Popinigis (1985) relata que estudos sobre a influência da quantidade de água no substrato, durante o processo germinativo, são importantes para as espécies em geral, tendo em vista que informações relacionadas à velocidade de hidratação mostram que este fator está ligado à disponibilidade hídrica, potencial mátrico do substrato, temperatura e características intrínsecas da semente.

Tabela 3. Índice de velocidade de germinação de sementes de melão, submetidas a diferentes temperaturas e volumes de água destilada no substrato de germinação. Janaúba, MG. 2012.

\begin{tabular}{ccccc}
\hline Volume de água & \multicolumn{3}{c}{ Temperatura $\left({ }^{\circ} \mathrm{C}\right)$} & Médias \\
\cline { 2 - 4 } destilada $(\mathrm{mL})$ & $20-30$ & 25 & 30 & 7,7 \\
\hline 1 & $7,2 \mathrm{~b}$ & $4,5 \mathrm{c}$ & $11,4 \mathrm{a}^{*}$ & 7,8 \\
1,5 & $5,7 \mathrm{~b}$ & $6,3 \mathrm{~b}$ & $11,5 \mathrm{a}$ & 8,2 \\
2 & $4,8 \mathrm{~b}$ & $9,3 \mathrm{a}$ & $10,7 \mathrm{a}$ & 8,3 \\
2,5 & $7,5 \mathrm{~b}$ & $7,9 \mathrm{ab}$ & $9,6 \mathrm{a}$ & 10,8 \\
3 & $9,7 \mathrm{~b}$ & $10,3 \mathrm{~b}$ & $12,4 \mathrm{a}$ & \\
\hline
\end{tabular}

*Médias seguidas por letras distintas nas linhas, diferem estatisticamente entre si pelo teste Tukey, a 5\% de probabilidade.

Fonte: Elaboração dos autores.

Semelhante aos dados obtidos na germinação (Figura 1), os resultados do índice de velocidade de germinação (Figura 2) evidenciaram respostas significativas quando se avaliou os volumes de água no substrato dentro de cada temperatura. A avaliação da velocidade de germinação, que caracteriza uma forma de se mensurar o vigor das sementes, permitiu diferenciar o efeito das temperaturas sobre a velocidade de germinação das sementes de melão, sendo que na temperatura de $30^{\circ} \mathrm{C}$ as sementes apresentaram maior velocidade no processo.

Para a temperatura de $25^{\circ} \mathrm{C}$, o modelo ajustado demonstrou aumento linear na velocidade 
de germinação à medida que se aumentava a disponibilidade de água no substrato. Já a temperatura de $20-30^{\circ} \mathrm{C}$ evidenciou comportamento quadrático, onde os resultados superiores foram verificados quando as sementes foram submetidas ao volume de água igual a 3,0 vezes o peso do substrato (Figura 2).

Figura 2. Índice de velocidade de germinação (IVG) de sementes de melão, submetidas a diferentes temperaturas e volumes de água destilada no substrato de germinação. Janaúba, MG. 2012.

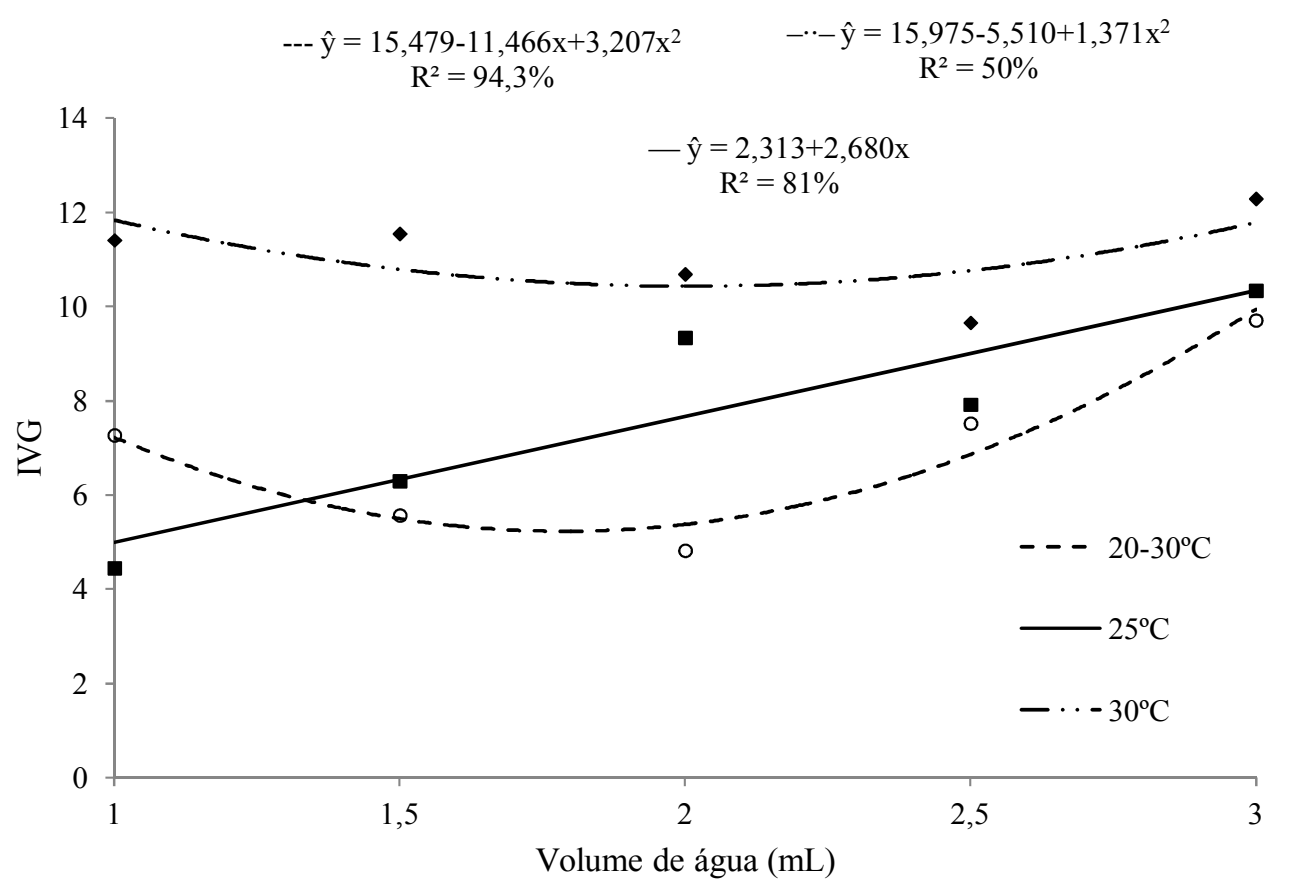

Fonte: Elaboração dos autores.

Em seu trabalho, Ramos, Varela e Melo (2006) verificaram que as quantidades de água adicionadas no substrato não apresentaram efeito significativo para os resultados de velocidade de germinação de Ochroma pyramidale. No entanto, ocorreu diferença para a temperatura, sendo que as maiores temperaturas foram mais favoráveis ao processo, como verificado no presente trabalho.

Como relatado, os volumes de água exerceram efeito sobre todas as variáveis analisadas. Durante o processo germinativo, a absorção de água causa o amolecimento do tegumento, o aumento do volume do embrião e dos tecidos de reserva, favorecendo a ruptura do tegumento, a difusão gasosa e a emergência da raiz primária. Proporciona, ainda, a diluição do protoplasma, permitindo a difusão de hormônios e, consequentemente, ativação de sistemas enzimáticos. Com isso, desenvolve-se a digestão, translocação e a assimilação das reservas, resultando no crescimento do embrião (MARCOS FILHO, 2005), com respostas também sobre o desempenho de plântulas.

Houve efeito significativo de temperaturas sobre o desempenho das plântulas de melão (Tabela 4). Em relação ao comprimento de raiz, a temperatura de $30^{\circ} \mathrm{C}$ proporcionou o melhor resultado, enquanto que as demais temperaturas não diferiram entre si. Para o comprimento de parte área, o melhor resultado também foi verificado quando as sementes foram expostas a $30^{\circ} \mathrm{C}$, enquanto que a temperatura 
alternada de $20-30^{\circ} \mathrm{C}$ proporcionou um menor desenvolvimento da parte aérea das plântulas.

Os resultados obtidos em laboratório podem ser utilizados para predizer o comportamento germinativo e desenvolvimento de plântulas em condições naturais. Nesse sentido, observa-se que a temperatura de $30^{\circ} \mathrm{C}$ foi mais favorável ao desempenho fisiológico das sementes, com respostas no desenvolvimento das plântulas. Isso porque, nota-se que ao trabalhar com temperatura próxima às observadas nos ambientes que a cultura do melão se adapta (regiões tropicais), as sementes demonstraram boa capacidade germinativa, podendo-se inferir que o teste de germinação realizado à temperatura de $30^{\circ} \mathrm{C}$ pode simular condições reais em que as sementes são submetidas durante a semeadura, crescimento e o desenvolvimento nos campos agrícolas, sendo uma temperatura recomendada para avaliação em laboratórios de análise de sementes.

O comprimento da raiz primária e da parte aérea das plântulas foram influenciados pela quantidade de água adicionada ao substrato (Figura 3). Para o comprimento de raiz, à medida que se elevou a quantidade de água no substrato, houve redução nos valores obtidos. Já para o comprimento de parte área, o aumento dos valores em resposta ao volume de água foi de pouca magnitude, variando de 3,13 a $3,69 \mathrm{~cm}$.

Tabela 4. Comprimento de raiz (CR) e de parte aérea (CPA), em centímetros, de plântulas de melão, submetidas a diferentes temperaturas. Janaúba, MG. 2012.

\begin{tabular}{ccccc}
\hline & \multicolumn{3}{c}{ Temperatura $\left({ }^{\circ} \mathrm{C}\right)$} & Médias \\
\cline { 2 - 4 } Variável & $20-30$ & 25 & 30 & 6,5 \\
CR & $5,2 \mathrm{~b}$ & $6,1 \mathrm{c}$ & $8,3 \mathrm{a}^{*}$ & 3,4 \\
\hline $\mathrm{CPA}$ & $1,5 \mathrm{c}$ & $4,1 \mathrm{~b}$ & $4,7 \mathrm{a}$ & \\
\hline
\end{tabular}

*Médias seguidas por letras distintas nas linhas, diferem estatisticamente entre si pelo teste Tukey, a 5\% de probabilidade. Fonte: Elaboração dos autores.

O desdobramento da interação V x T, estudando o efeito de temperaturas dentro de cada volume de água no substrato, revelou comportamento diferenciado entre as temperaturas analisadas quando se avaliou a massa fresca de plântulas (Tabela 5). Resultados superiores foram verificados quando se utilizou a temperatura de $30^{\circ} \mathrm{C}$ em todos os volumes de água estudados, em conformidade com as demais variáveis analisadas. Certamente esses resultados podem sem explicados uma vez que a temperatura foi favorável para o processo germinativo, com resposta positiva para a massa fresca de plântulas. Sementes mais vigorosas, com melhor desempenho fisiológico, originarão plântulas com maiores taxas de desenvolvimento e ganho de massa em função destas apresentarem maior capacidade de transformação dos tecidos. 
Figura 3. Comprimento de raiz (CR) e de parte aérea (CPA), em centímetros, de plântulas de melão (médias das 3 temperaturas), submetidas a diferentes volumes de água destilada no substrato de germinação. Janaúba, MG. 2012.

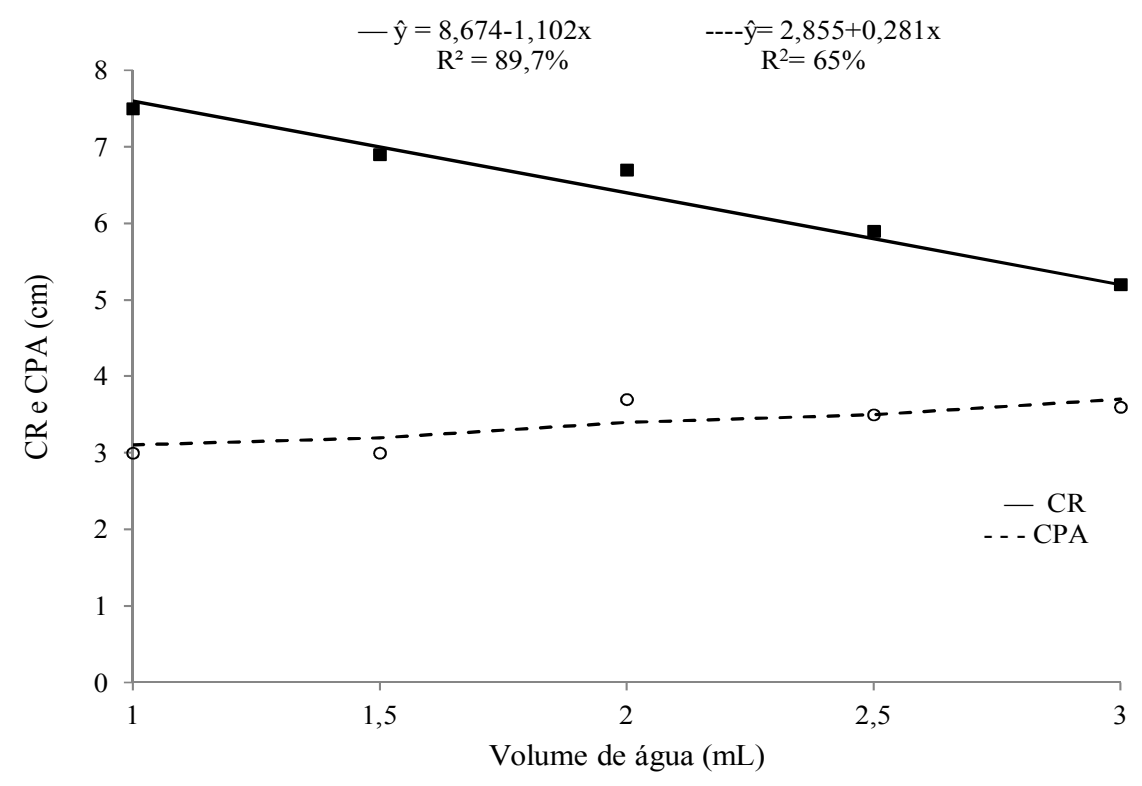

Fonte: Elaboração dos autores.

Tabela 5. Massa fresca ( $\mathrm{g}$ ) de plântulas de melão, submetidas a diferentes temperaturas e volumes de água destilada no substrato de germinação. Janaúba, MG. 2012.

\begin{tabular}{ccccc}
\hline \multirow{2}{*}{$\begin{array}{c}\text { Volume de água } \\
\text { destilada }(\mathrm{mL})\end{array}$} & \multicolumn{3}{c}{ Temperatura $\left({ }^{\circ} \mathrm{C}\right)$} & Médias \\
\cline { 2 - 4 } & $20-30$ & 25 & 30 & 7,32 \\
1 & $3,1 \mathrm{~b}$ & $1,3 \mathrm{c}$ & $5,9 \mathrm{a}^{*}$ & 2,91 \\
2 & $1,2 \mathrm{c}$ & $2,2 \mathrm{~b}$ & $5,3 \mathrm{a}$ & 4,24 \\
2,5 & $1,2 \mathrm{c}$ & $3,0 \mathrm{~b}$ & $4,2 \mathrm{a}$ & 2,71 \\
3 & $1,7 \mathrm{~b}$ & $2,3 \mathrm{~b}$ & $4,1 \mathrm{a}$ & 4,24 \\
\hline
\end{tabular}

*Médias seguidas por letras distintas nas linhas, diferem estatisticamente entre si pelo teste Tukey, a 5\% de probabilidade.

Fonte: Elaboração dos autores.

De acordo com Carvalho e Nakagawa (2000), a temperatura afeta o processo germinativo de três maneiras: sobre o total de germinação, sobre a velocidade de germinação e sobre a uniformidade de germinação. Temperaturas acima da ótima para o total de germinação aceleram a velocidade do processo, mas desorganiza-o e o número de sementes que conseguem completá-lo cai rapidamente, e, temperaturas abaixo da ótima reduzem a velocidade da germinação, expondo as plântulas às condições adversas do ambiente (GUIMARÃES; OLIVEIRA; VIEIRA, 2006).

Não houve efeito de temperaturas e volume de água sobre a massa seca de plântulas (dados não apresentados). Em sementes de Rafhanus sativus submetidas a diferentes temperaturas, Nery, Carvalho e Fraga (2009) também verificaram 
influência deste fator ambiental sobre o acúmulo de massa seca em plântulas.

Os resultados do efeito da umidade do substrato para cada temperatura, avaliando a massa fresca de plântulas, encontram-se na Figura 4. Resultados superiores foram verificados para a temperatura de $30^{\circ} \mathrm{C}$, observando redução na massa fresca de plântulas até o volume de água de 2,0 vezes o peso do substrato, sendo que a partir desse ponto, houve incremento no ganho de massa fresca. Para a temperatura de $25^{\circ} \mathrm{C}$ houve comportamento linear, com aumento no ganho de massa fresca à medida que aumenta o volume de água no substrato, enquanto que para a temperatura de $20-30^{\circ} \mathrm{C}$, os melhores resultados foram obtidos quando se utilizou o substrato mais úmido (3,0 vezes o peso do substrato seco). Entretanto, em relação às outras temperaturas, o teste de germinação a $30^{\circ} \mathrm{C}$ foi mais eficiente no desempenho das sementes, o que certamente originou plântulas com maiores taxas de desenvolvimento e ganho de massa em função destas apresentarem maior capacidade de transformação dos tecidos e suprimento das reservas armazenadas.

Figura 4. Massa fresca (g) de plântulas de melão, submetidas a diferentes temperaturas e volumes de água destilada no substrato de germinação. Janaúba, MG. 2012.

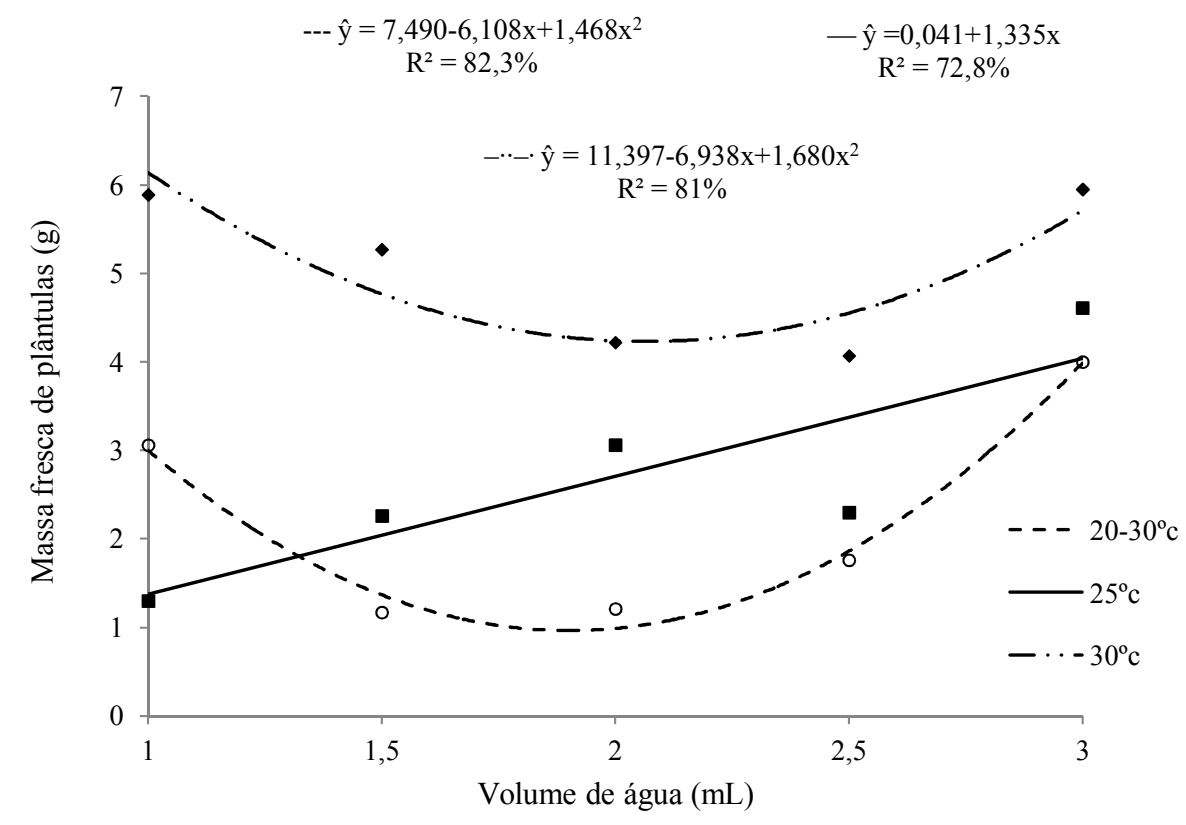

Fonte: Elaboração dos autores.

Devido à importância da utilização da quantidade certa de água para a germinação, as Regras para Análise de Sementes (BRASIL, 2009) passaram a normatizar o umedecimento do substrato, recomendando para o teste de germinação em papel a adição de um volume de água equivalente a 2,0 até 2,5 vezes (gramínea) ou 2,5 a 3,0 vezes (leguminosa) o peso do substrato seco. Em areia, é recomendado o umedecimento com até 50 e $60 \%$ da capacidade de retenção de água no substrato, para sementes de cereais e de leguminosas, respectivamente. Conforme já relatado, as recomendações não atendem a todas as espécies, principalmente aquelas com dificuldade para germinar. 
Os estudos de germinação, relacionados ao nível de umidade do substrato, são importantes na tecnologia de sementes de espécies olerícolas, principalmente em função do alto custo das sementes dessas espécies, contribuindo para auxiliar na condução dos testes de germinação e redução da discrepância entre os resultados obtidos em laboratório. Nesse sentido, a combinação ideal da temperatura e volume de água que favoreça a germinação, provavelmente minimizaria as variações nos resultados dos testes, garantindo resultados mais confiáveis ao produtor.

Diante dos resultados, conclui-se que as combinações de volume de água destilada no substrato e a temperatura de exposição que proporcionam melhores respostas na germinação e no vigor das sementes de melão, variedade pepino, são de 1,0 vez o peso do substrato seco na temperatura de $30^{\circ} \mathrm{C}$ e 3,0 vezes o peso do substrato seco a 25 e $20-30^{\circ} \mathrm{C}$.

Dentre as temperaturas estudadas, a temperatura de $30^{\circ} \mathrm{C}$ promove melhores respostas em todas as variáveis analisadas, sendo recomendada como temperatura adicional para avaliação da qualidade fisiológica de sementes de melão.

\section{Agradecimentos}

À Fundação de Amparo à Pesquisa do Estado de Minas Gerais (FAPEMIG) e à Universidade Estadual de Montes Claros (UNIMONTES), pelo apoio financeiro para o desenvolvimento deste trabalho.

\section{Referências}

ALVES, E. U.; OLIVEIRA, A. P.; BRUNO, R. L. A.; SADER, R.; ALVES, A. U. Rendimento e qualidade fisiológica de sementes de coentro cultivado com adubação orgânica e mineral. Revista Brasileira de Sementes, Brasília, v. 27, n. 1, p. 132-137, 2005.
AZEREDO, G.A.; SILVA, B. M. S.; SADER, R.; MATOS, V. P. Umedecimento e substratos para germinação de sementes de repolho. Pesquisa Agropecuária Tropical, Goiás, v. 40, n. 1, p. 77-82, 2010.

BRASIL. Ministério da Agricultura, Pecuária e Abastecimento. Regras para análise de sementes. Brasília: SNDA/DNDV/CLAV. 2009. 365 p.

CARVALHO, M. L. M.; FRANÇA NETO, J. B.; KRZYZANOWSKI, F. C. Controle de qualidade na produção de sementes. Informe Agropecuário, Belo Horizonte, v. 27, n. 232, p. 52-58, 2006.

CARVALHO, N. M.; NAKAGAWA, J. (Ed.). Sementes: ciências, tecnologia e produção. 4. ed. Jaboticabal: FUNEP, 2000. 588 p.

COSTA, N. D. O cultivo do melão. São Roque: HortiBrasil. 2005. Disponível em: <http://www. hortibrasil.org.br/jnw/images/stories/Melao/m.69.pdf > . Acesso em: 8 fev. 2012.

GANGULI, S.; SEN-MANDI, S. Effects of ageing on amylase activity and scutellar cell structure during imbibition in wheat seed. Annals of Botany, London, v. 71, n. 5, p. 411-416, 1993.

GENTIL, P. F.; TORRES, S. B. Umedecimento do substrato e germinação de sementes de maxixe (Cucumis anguria L.). Revista Brasileira de Sementes, Brasília, v. 23, n. 2, p. 113-116, 2001.

GUIMARÃES, R. M.; OLIVEIRA, J. A.; VIEIRA, A. R. Aspectos fisiológicos de sementes. Informe Agropecuário, Belo Horizonte, v. 27, n. 232, p. 40-50, 2006.

MACHADO, C. F.; OLIVEIRA, J. A.; DAVIDE, A. C.; GUIMARÃES, R. M. Metodologia para a condução do teste de germinação em ipê-amarelo. Revista Cerne, Lavras, v. 8, n. 2, p.17-25, 2002.

MAGUIRE, J. D. Speed of germination-aid in selection and evaluation for seedling emergence and vigor. Crop Science, Madison, v. 2, n. 1, p. 176-177, 1962.

MARCOS FILHO, J. Fisiologia de sementes de plantas cultivadas. Piracicaba: FEALQ, 2005. 495 p.

NERY, M. C.; CARVALHO, M. L. M.; FRAGA, A. C. Adequação do teste de germinação para sementes de nabo forrageiro. Revista Brasileira de Sementes, Brasília, v. 31, n. 2, p. 177-187, 2009.

POPINIGIS, F. Fisiologia da semente. 2. ed. Brasília: AGIPLAN, 1985. 289 p. 
RAMOS, M. B. P.; VARELA, V. P.; MELO, M. F. F. Influência da temperatura e da quantidade de água no substrato sobre a germinação de sementes de Ochroma pyramidale (Cav. ex Lam.) Urban (pau-de-balsa). Acta Amazônica, Manaus, v. 36, n. 1, p. 103-106, 2006.
VARELA, V. P.; RAMOS, M. B. P.; MELO, M. F. F. Umedecimento do substrato e temperatura na germinação de sementes de angelim-pedra (Dinizia excelsa Ducke). Revista Brasileira de Sementes, Brasília, v. 27, n. 2, p. 130-145, 2005.

VICENTE, M.; NORONHA, A.; SILBERSCHMIDT, $\mathrm{K}$. Substrate moisture levels for germination testing of some agricultural seeds. Anais da Academia Brasileira de Ciências, Rio de Janeiro, v. 41, n. 4, p. 633-639, 1969. 